American J. of Engineering and Applied Sciences 5 (1): 59-62, 2012

ISSN 1941-7020

(C) 2014 Wannahari and Nordin, This open access article is distributed under a Creative Commons Attribution

(CC-BY) 3.0 license

\title{
The Recovery of Used Palm Cooking Oil Using Bagasse as Adsorbent
}

\author{
Rizki Wannahari and Mariam Firdhaus Mad Nordin \\ Department of Environmental Technology, \\ Faculty Agro Industry and Natural Resources, \\ University Malaysia Kelantan, Malaysia
}

\begin{abstract}
Problem statement: The use and reduce cooking oil is a common phenomena in our society. While some of this cooking oil is further refine most of it however and not subject to any filtration in the refining process medium such as carbon active, silica are commonly use. Approach: The used of bagasse as adsorbent is not common. This is odd especially when structural component of bagasse which is made up of carbon material is suitable as adsorbent and the fact that, adsorbent bagasse further reduce solid waste disposal and hence reducing one source of environmental pollution. Results: This study was undertaken to explore the possibility of using bagasse as adsorbent. Specifically, bagasse is being experimented to reduce the harmful content such as Free Fatty Acid (FFA) and color density in used cooking oil. The variation of adsorbent weight and contact time are used in this research as parameters to determine the effective time and the amount of adsorbent that should be used in the oil refining process. From the experiment conducted, it can be established that bagasse when use as an adsorbent can reduce FFA to $82.14 \%$ which is lower the harmful limit. Conclusion/Recommendations: This result is obtained when using 7.5 gr of bagasse for 60 $\mathrm{m}$ contact time. Similarly, the color of oil is reduced to $75.67 \%$ which is significant and this is base on $10 \mathrm{gr}$ of bagasse with $60 \mathrm{~m}$ of contact time.
\end{abstract}

Key word: Free Fatty Acid (FFA), common phenomena, Refined Bleached Deodorization (RBD), aluminum hydroxide gel, natural adsorbent made, refining process, structural component

\section{INTRODUCTION}

The continue use and reuse of cooking oil (palm oil) is common in our society today. There are several reasons for this habit. The perception of some people that the food will be more delicious when fried using used oil and also for economic reasons are most common. During the frying process, oil will experience degradation reactions caused by heat, air and water, resulting in oxidation, hydrolysis and polymerization. Degradation reaction products contained in this oil will reduce the quality of the oil and cause adverse effects to humans (Bhattacharya and Singhal, 2008).

The parameters used in measuring the quality of used cooking oil in this research are the Free Fatty Acid (FFA), amount of hydrolysis and the color darker is effect from oxidation. Recycling used cooking oil using adsorbents, such as silica gel, magnesium oxide, aluminum hydroxide gel and activated clay, has been studied before (McNeill, 1986; Lin and Reynolds, 1998; Maskan and Halill, 2003; Agus, 2009; Aini et al., 1992; Chow, 2000; Commission, 1999; Gunstone, 2009; Judith et al., 2011; Kheang et al., 2006; Ranganna, 1986; Richard and Brien, 2009; Simons,
2007; Slamet et al., 1990; Loh et al., 2006) for improving the quality parameter of used cooking oil.

This research attempt to explore the use of natural adsorbent made up of bagasse from sugarcane juice waste to recover the used cooking oil. Structural component of bagasse made up from carbon material makes bagasse suitable as adsorbent. For each 10 tons of sugarcane crushed, a sugar factory produces nearly 3 tones of wet bagasse (Pandey and Careney, 2008).

Recycling of disposed oils and waste products from sugarcane juice into purified frying oil and bagasse to be used as adsorbent are expected to reduce waste disposal problems that are consistent with the current discussion today and decrease the prospect of endangering the ecosystem.

\section{MATERIALS AND METHODS}

Design of experiment: In this study Statistical Analysis Software (SAS) is used to determine initial design and analysis of data. By entering the weight factor and time, FFA and color as a variable, SAS will provide the experimental design such as follows Table 1.

Corresponding Author: Rizki Wannahari, Department of Chemical and Environmental Engineering, University Malaysia Kelantan 
Materials and equipment: The materials used are derived from waste from sugarcane juice (bagasse) usually obtain from stall selling sugarcane juice. The used cooking oil on the other hand is based on cooking oil that has been condition by the researcher. Activation of bagasse will be using $\mathrm{NaOH}$ solution. The instrument used is a Whatman filter paper \# 41, Thermometer, Rotary evaporator, Spectrophotometer, Chemical laboratory support equipment Such as mixers, electric stove, Erlenmeyer, pipettes drops, balance sheet measuresand weights.

The Flowchart Fig. 1 illustrate the stages of research:

Preparation of bagasse adsorbentseveral steps as follows must be done before the activation:

- Bagasse fibers wash with water to remove sand, soil or other regulators

- Bagasse fibers that have been dried milled with a grinder into powder and sifted to obtain a diameter of $<600 \mu \mathrm{m}$

To activate bagasse, the first thing to do is to heat the bagasse at $200^{\circ} \mathrm{C}$ for $120 \mathrm{~m}$ in oven. It is then activated with $\mathrm{NaOH}$ solution and heated for another $1.5 \mathrm{~h}$. Next is to Filter the mixture and then to heat them again at $200^{\circ} \mathrm{C}$ for $90 \mathrm{~m}$.

Preparation of used cooking oil: 1 liter of used cooking oil that was previously used to fry potatoes, chicken and dried fish.

Purification Used cooking oil: Method of oil purification with adsorbent according to (Yustinah, 2009) research is described in the flowchart Fig. 2.

Determination of FFA: Determination of FFA values using the method of AOCS, 2009. About 28, $2 \mathrm{~g}$ well mixed oil add with $50 \mathrm{~mL}$ hot ethyl alcohol and $1 \%$ phenolphthalein. The mixture was titrated with $0.1 \mathrm{~N}$ $\mathrm{NaOH}$ with vigorous shaking until a permanent faint pink appeared and persisted at least for $1 \mathrm{~min}$. The FFA content is calculated as percentage of oleic acid:

$\% \mathrm{FFA}=(\mathrm{V} \times \mathrm{N} \times 28.2) / \mathrm{m}$

where, $\mathrm{m}$ is the mass of the test portion, in grams, $\mathrm{N}$ the normality of $\mathrm{NaOH}$ and $\mathrm{V}$ the volume of $\mathrm{NaOH}$ consumed, in milliliters.

Color: Determination of color differences using the reading level is shown by a spectrophotometer absorbance.

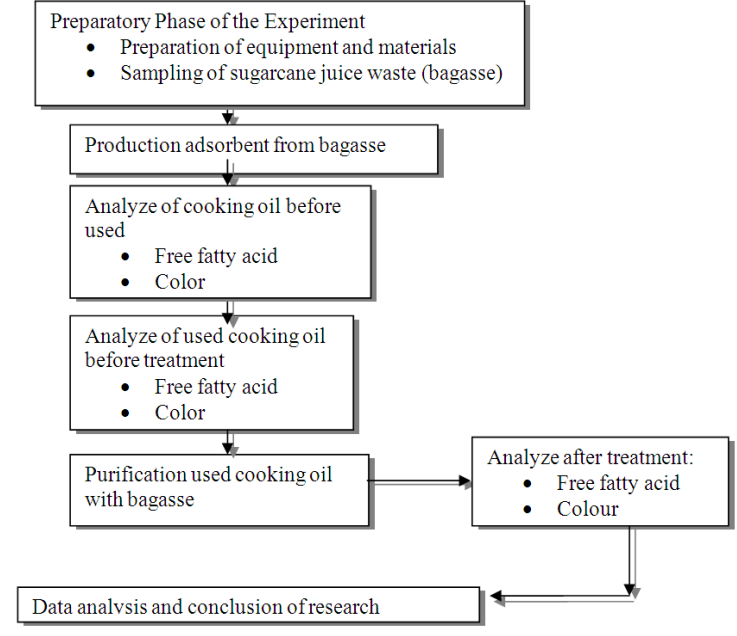

Fig. 1: Flow Chart of experiment

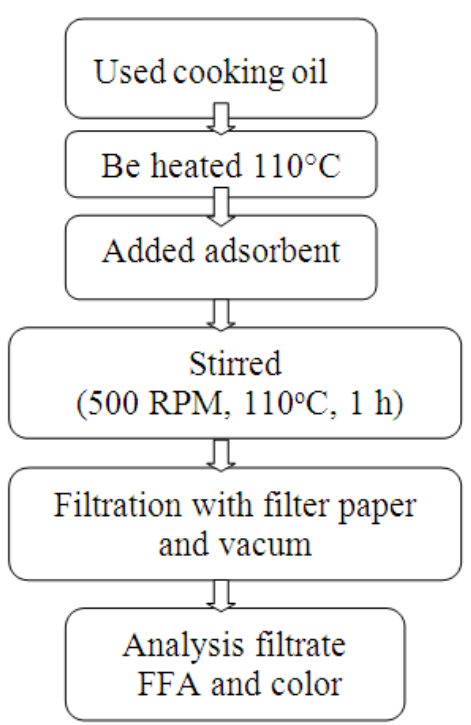

Fig. 2: Flow Chart of used oil purification process

Table 1: Design of experiment

\begin{tabular}{lrll}
\multicolumn{2}{l}{ Table 1: Design of experiment } & & \\
\hline Time & Weight & FFA & Color \\
\hline 10 & 5.0 & & \\
10 & 10.0 & & \\
60 & 5.0 & & \\
60 & 10.0 & & \\
10 & 7.5 & & \\
60 & 7.5 & & \\
35 & 5.0 & & \\
35 & 10.0 & & \\
35 & 7.5 & & \\
35 & 7.5 & & \\
35 & 7.5 & & \\
35 & 7.5 & & \\
35 & 7.5 & & \\
\hline
\end{tabular}




\section{RESULTS AND DISCUSSION}

From the 177 gr of bagasse was activated to produce $66.39 \mathrm{gr}$. This is a severe reduction of $62.5 \%$ due to the heating process. About $150 \mathrm{~mL}$ used cooking oil was mixed with various weight of adsorbent which is predetermined and then continued with the purifying process at various contact time as determined.

Based on established experimental design, FFA values obtained are Table 2 and Fig. 3.

The maximum standards for FFA value in the cooking oil released by Palm Oil Refiners Association of Malaysia (PORAM) for Refined, Bleached, Deodorization (RBD) Palm Oil is $0.1 \%$. Base on this standard, treated used cooking oil at various condition resulted in the allowable limits. The highest percentage reduction of FFA is obtained at 60 -min contact time and 7.5 gr adsorbent used, producing a reduction to $82.144 \%$.

The experiment also proof that weights variation of bagasse used is of no significant. This is as per the Table 3.

The Optimization Result of FFA supported by SAS, states that the titration reading is in units smaller than $0.05 \mathrm{~mL}$. This will produce accurate results and prove the significance of data. However, results obtained in the study are based on units of 0.05 , which reduces the accuracy and this is due to the limited equipment available.

Predictive models: From the data obtained. If time is $\alpha, \beta$ is weight so the value of FFA is:

$$
\begin{aligned}
& \text { FFA } 0.1134+0.000073 \alpha-0.017886 \beta-6.01 \\
& \text { E-6 } \alpha^{2}-0.000018 \alpha \beta+0.001215 \beta^{2}
\end{aligned}
$$

Color: The data obtained from the measurement of color density through absorbance spectrophotometer readings are Table 4 and Fig. 4.

Base on the analysis as illustrated above, it can be seen that the highest reduction of color density is when $10 \mathrm{gr}$ of baggase is used with a contact time of $60 \mathrm{~m}$. Base on ANOVA analysis shown in Table 5, it can be established that the result obtain are significant. This means that there is effect of weight variation and time on the recovery process used cooking oil.

Predictive model for color density: From the data obtained, if the time is $\alpha, \beta$ is weight. The color density can be obtained from:

Color $=0.032233+0.000193 \alpha-$ $0.004867 \beta-0.00004 \alpha \beta+0.000373 \beta^{2}$

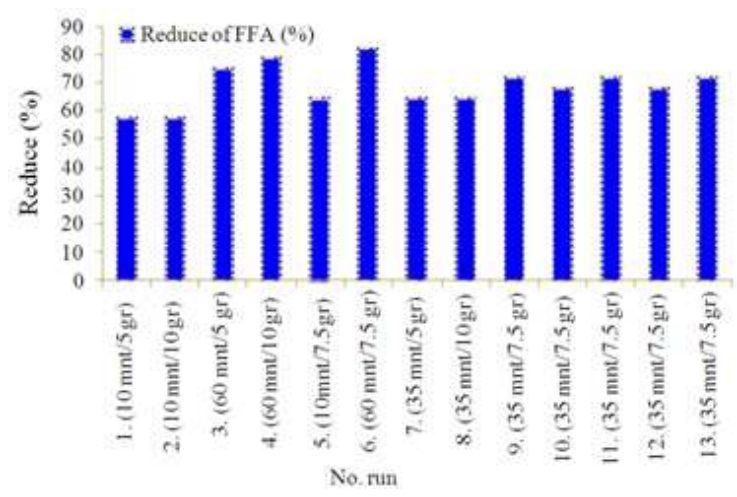

Fig. 3: Percentage reduction of FFA

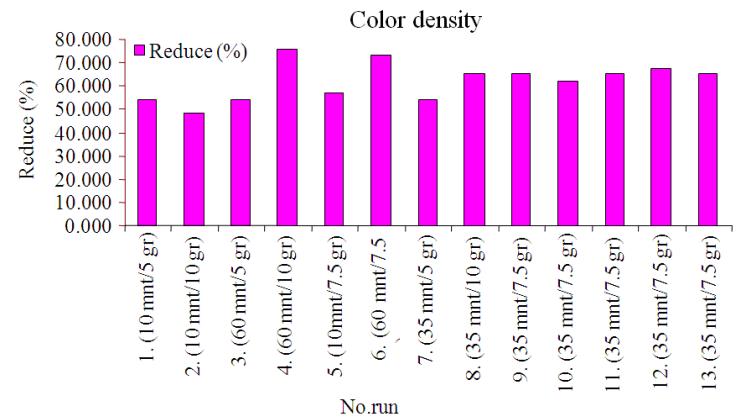

Fig. 4: Percentage reduction of color density

Table 2: FFA value and $\%$ of reduce

\begin{tabular}{lrlll}
\hline Time & Weight & mL Naoh & FFA $(\%)$ & Reduce $(\%)$ \\
\hline New cooking oil & & 0.20 & 0.0182 & control \\
Used cooking oil & & 1.40 & 0.1271 & - \\
10 & 5.0 & 0.60 & 0.0545 & 57.145 \\
10 & 10.0 & 0.60 & 0.0545 & 57.145 \\
60 & 5.0 & 0.35 & 0.0318 & 75.002 \\
60 & 10.0 & 0.30 & 0.0272 & 78.573 \\
10 & 7.5 & 0.50 & 0.0454 & 64.288 \\
60 & 7.5 & 0.25 & 0.0227 & 82.144 \\
35 & 5.0 & 0.50 & 0.0454 & 64.288 \\
35 & 10.0 & 0.50 & 0.0454 & 64.288 \\
35 & 7.5 & 0.40 & 0.0363 & 71.430 \\
35 & 7.5 & 0.45 & 0.0409 & 67.859 \\
35 & 7.5 & 0.40 & 0.0363 & 71.430 \\
35 & 7.5 & 0.45 & 0.0409 & 67.859 \\
35 & 7.5 & 0.40 & 0.0363 & 71.430 \\
\hline
\end{tabular}

Table 3: ANOVA for FFA

\begin{tabular}{lr}
\hline Source & Pr $>\mathrm{F}$ \\
\hline Time & $<0.0001$ \\
Weight & 0.3888 \\
Time $\times$ weight & 0.2976 \\
\hline
\end{tabular}


Am. J. Engg. \& Applied Sci., 5 (1): 59-62, 2012

Table 4: Level of color density

\begin{tabular}{llll}
\hline Time & Weight & Absorbance & Reduce $(\%)$ \\
\hline New Cooking oil & & Blank & Blank \\
Used Cooking oil & & 0.037 & - \\
10 & 5.0 & 0.017 & 54.054 \\
10 & 10.0 & 0.019 & 48.649 \\
60 & 5.0 & 0.017 & 54.054 \\
60 & 10.0 & 0.009 & 75.676 \\
10 & 7.5 & 0.016 & 56.757 \\
60 & 7.5 & 0.010 & 72.973 \\
35 & 5.0 & 0.017 & 54.054 \\
35 & 10.0 & 0.013 & 64.865 \\
35 & 7.5 & 0.013 & 64.865 \\
35 & 7.5 & 0.014 & 62.162 \\
35 & 7.5 & 0.013 & 64.865 \\
35 & 7.5 & 0.012 & 67.568 \\
35 & 7.5 & 0.013 & 64.865 \\
\hline
\end{tabular}

Table 5: ANOVA for color

\begin{tabular}{ll}
\hline Source & Pr $>\mathrm{F}$ \\
\hline Time & $<0.0001$ \\
Weight & 0.0002 \\
Time $\times$ weight & $<0.0001$ \\
\hline
\end{tabular}

\section{CONCLUSION}

Adsorbent made from bagasse is potential in the process recovery of used cooking oil. The bagasse adsorbent can decrease FFA up to $82.14 \%$ and reduce the color density up to $75.67 \%$. From $150 \mathrm{ml}$ of used cooking oil sample, time effective for treatment to reduce FFA and color density is about $60 \mathrm{~m}$. The effective weight of bagasse which has been used for the reduction of FFA is $7.5 \mathrm{~g}$, while the reduction of color density level requires $10 \mathrm{~g}$ of bagasse adsorbent.

\section{REFERENCES}

Agus, B., 2009. Pemanfaatan ampas tebu hasil samping pabrik gula menjadi karbon aktif sebagai adsorben $\mathrm{Cu}^{+2}$. Universities Negeri Malang, Malang

Aini, I.N., A. Abdullah and A.H. Halim, 1992. Evaluation of palm oil quality: correlating sensory with chemical analyses. J. Am. Oil Chem. Soc., 69: 272-275. DOI: 10.1007/BF02635900

Bhattacharya, S and T. Singhal, 2008. Regeneration of thermally polymerized frying oils with adsorbents. J. food chemistry, 110: 562-570. DOI: 10.1016/j.foodchem.2008.02.033
Chow, C.K., 2000. Fatty Acids in Foods and their Health Implications. 2nd Edn., M. Dekker, New York, ISNB: 0824767829, pp: 1045.

Commission, C.A., 1999. Recommended International Standard for Named Vegetable Oils. 1st Edn., Codex Stan., FAO and WHO, Rome, Italy, pp: 210.

Gunstone, F., 2009. Oils and Fats in the Food Industry. 1st Edn., John Wiley and Sons, Chichester, ISBN: 1444302434, pp: 160.

Judith, K., R. Carle and D.R. Kammerer, 2011. Adsorption and ion exchange: Basic principles and their application in food processing. J. Agric. Food Chem., 59: 22-42. DOI: 10.1021/jf1032203

Kheang, S.L., C.Y. May, C.S. Foon and M.A. Ngan, 2006. Recovery and conversion of palm oleinderived used frying oil to methyl esters for biodiesel. J. Oil Palm Res., 18: 247-252.

Loh, S.K., S.M. Chew and Y.M. Choo, 2006. Oxidative stability and storage behavior of fatty acid methyl esters derived from used palm oil. Journal of the Am. Oil Chemists' Soc., 83: 947-952. DOI: 10.1007/s11746-006-5051-9

Maskan, M and B. Halill, 2003. Effect of different adsorbents on purification of used sunflower seed oil utilized for frying. J. Eur Food Res. Technol., 217: 215-218. DOI: 10.1007/s00217-003-0731-2

Pandey, G.N and G.C. Carney, 2008. Environmental Engineering. 1st Edn., McGraw-Hill, New Delhi.

Ranganna, S., 1986. Handbook of Analysis and Quality Control for Fruit and Vegetable Products. 2nd Edn., Tata McGraw-Hill, New Delhi, ISBN-10: 0074518518, pp: 1112.

Richard, D. and O. Brien, 2009. Fat and oil. CRC Press: New York. Simons, S.J.R., 2007. Concepts of Chemical Engineering 4 Chemists. 1st Edn., Royal Society of Chemistry, ISBN: 0854049517, pp: 350.

Slamet, S., H. Bambang and Suhardi, 1990. Prosedur Analis Untuk Bahan Makanan dan Pertanian. Yogyakarta, Liberty.

Yustinah, 2009. Pengaruh massa Adsorben chitin pada penurunan kadar asam lemak bebas, bilangan peroksida dan warna gelap minyak. Universities Muhammadiyah, Jakarta. 